\title{
Amalgam Surface Treatment by Different Output Powers of Er:YAG Laser:SEM Evaluation
}

\author{
Mohammad Hashem Hosseini ${ }^{1}$, Mehdi Hassanpour ${ }^{2}$, Ardavan Etemadi ${ }^{3}$, Ladan Ranjbar Omrani ${ }^{4}$, \\ Hojat Darvishpour ${ }^{1}$, Nasim Chiniforush ${ }^{3 *}$ \\ ${ }^{1}$ Department of Orthodontics, School of Dentistry, Tehran University of Medical Sciences, Tehran, Iran \\ ${ }^{2}$ Department of Orthodontics, School of Dentistry, Qom University of Medical Sciences, Qom, Iran \\ ${ }^{3}$ Laser Research Center of Dentistry, Dental Research Institute, Tehran University of Medical Sciences, Tehran, Iran \\ ${ }^{4}$ Department of restorative, School of Dentistry, Tehran University of Medical Sciences, Tehran, Iran
}

\author{
*Correspondence to \\ Nasim Chiniforush, DDS; PhD \\ Candidate of Laser Dentistry, Laser \\ Research Center of Dentistry, School of \\ Dentistry, Tehran University of Medical \\ Sciences, Tehran, Iran. \\ Tel: $+98-2188994824$ \\ Fax: +98-2188994824 \\ Email: n-chiniforush@farabi.tums.ac.i
}

Published online 27 October 2015

\begin{abstract}
Introduction: The purpose of this study was to evaluate amalgam surfaces treated by different output powers of erbium-doped yttrium aluminum garnet (Er:YAG) laser by scanning electron microscope (SEM).

Methods: Twenty-one amalgam blocks ( $8 \mathrm{~mm} \times 8 \mathrm{~mm}, 3 \mathrm{~mm}$ thickness) were prepared by condensing silver amalgam (into putty impression material. After keeping them for 24 hours in distilled water, they were divided into 7 groups as follow: G1: Er:YAG laser (1 W, 50 mJ), G2: Er:YAG laser (2 W, 100 mJ), G3: Er:YAG laser (3 W, 150 mJ), G4: Sandblast, G5: Sandblast + Er:YAG laser (1 W, 50 mJ), G6: Sandblast +Er:YAG laser (2 W, $100 \mathrm{~mJ})$ and G7: Sandblast +Er:YAG laser (3 W, $150 \mathrm{~mJ})$. Then after preparation of all samples, they were examined by SEM.

Results: The SEM results of amalgam surfaces treated by different output powers of Er:YAG laser showed some pitting areas with non-homogenous irregularities

Conclusion: It seems that the application of sandblasting accompanied by Er:YAG laser irradiation can provide proper surface for bonding of orthodontic brackets.

Keywords: Amalgam; Orthodontic bracket; Er:YAG lasers.
\end{abstract}

\section{Introduction}

Recently, orthodontic treatment has increased among adults. Most of these patients have amalgam restorations on posterior teeth which are considered a big challenge for orthodontist regarding the bonding procedure. ${ }^{1,2}$

In order to achieve desirable bonding to amalgam, different studies were performed including various surface treatments and the application of different types of resins and adhesives. ${ }^{3,4}$

Surface treatment can be done by diamond bur, sandblasting, and chemical corrosion to improve bonding to amalgam surface. ${ }^{5}$

The application of lasers for treatment of dental substrate has gained special attention. Among different lasers, Erbium family lasers are used for treatment of dental hard tissues. ${ }^{6}$

It was shown that erbium-doped yttrium aluminum garnet (Er:YAG) laser with a wavelength of $2940 \mathrm{~nm}$ can ablate amalgam surface and produce micro craters. ${ }^{7}$ On the other hand, Oskoee et $\mathrm{al}^{8}$ in assessing the bonding of orthodontic brackets to silver amalgam treated by erbium, chromium doped yttrium scandium gallium garnet (Er-Cr:YSGG) laser compared to the sandblasting technique concluded that laser treatment increased the shear bond strength of stainless steel orthodontic brackets to amalgam restorations. ${ }^{8}$

The aim of this study was to evaluate amalgam surfaces treated by different output powers of Er:YAG laser by scanning electron microscope (SEM).

\section{Methods}

Twenty-one amalgam blocks $(8 \mathrm{~mm} \times 8 \mathrm{~mm}, 3 \mathrm{~mm}$ thickness) were prepared by condensing silver amalgam (Kerr, Germany) into putty impression material (Speedex, Colten, Switzerland) and burnishing with instruments. The samples were kept in distilled water at room temperature for 24 hours. Then, the samples were randomly divided into 7 groups (Table 1).

Er:YAG laser was used with a pulse rate of $20 \mathrm{~Hz}, 4 \mathrm{~mm}$ above the surface accompanied by water and air spray in all laser groups. Pulse duration was $230 \mu$ sec in all groups. All the surface area was treated by laser with a beam diameter of $1 \mathrm{~mm}$.

Sandblasting was done with $\mathrm{Al}_{2} \mathrm{O}_{3}$ particle size $50 \mu$, from $10 \mathrm{~mm}$ above the surface, with a pressure of 60 Psi for 5 seconds.

In G5, G6 and G7, laser irradiation was done after sandblasting. Then, all samples were prepared for SEM (TES-

Please cite this article as follows: Hosseini MH, Hassanpour M, Etemadi A, Ranjbar Omrani L, Darvishpour H, Chiniforush N. Amalgam surface treatment by different output powers of Er:YAG laser:SEM evaluation. J Lasers Med Sci. 2015;6(4):171-173. doi:10.15171/jlms.2015.14. 
CAN VEGA, USA) evaluation at x1000, x2000 and x5000.

\section{Results}

The SEM results of amalgam surfaces treated by different output powers of Er:YAG laser showed some pitting areas with non-homogenous irregularities (Figures 1-3).

Figure 4 showed sandblasted amalgam surface with scratch- like irregularities.

More irregularities were achieved in sandblast + laser irradiation (Figures 4-6).

Table 1. Study Groups

\begin{tabular}{ll}
\hline Groups & Treatment \\
\hline G1 & Er:YAG laser $(1 \mathrm{~W}, 50 \mathrm{~mJ})$ \\
G2 & Er:YAG laser $(2 \mathrm{~W}, 100 \mathrm{~mJ})$ \\
G3 & Er:YAG laser $(3 \mathrm{~W}, 150 \mathrm{~mJ})$ \\
G4 & Sandblast \\
G5 & Sandblast + Er:YAG laser (1 W, $50 \mathrm{~mJ})$ \\
G6 & Sandblast +Er:YAG laser (2 W, $100 \mathrm{~mJ})$ \\
G7 & Sandblast +Er:YAG laser (3 W, $150 \mathrm{~mJ})$ \\
\hline
\end{tabular}
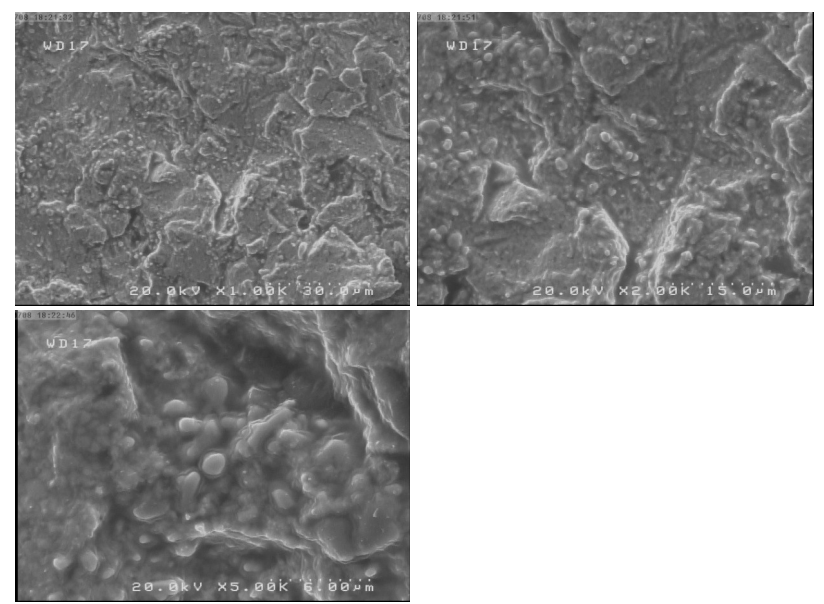

Figure 1. Amalgam surface treated by Er:YAG laser with output power of $1 \mathrm{~W}, 50 \mathrm{~mJ}$ (Original magnification $\times 1000, x 2000$, and $x 5000)$.
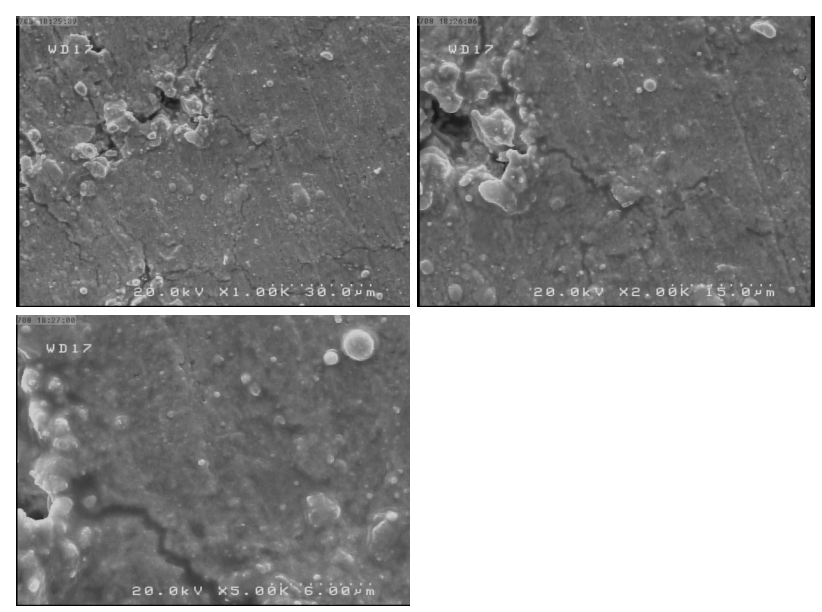

Figure 2. Amalgam surface treated by Er:YAG laser with output power of $2 \mathrm{~W}, 100 \mathrm{~mJ}$ (Original magnification $\times 1000, \times 2000$, and $x 5000)$.

\section{Discussion}

Providing suitable bond strength between brackets and amalgam is one of the challenging problems in orthodontics. ${ }^{9}$

The purpose of this study was to evaluate amalgam surfaces treated by different powers of Er:YAG laser compared to laser irradiation following sandblasting in a qualitative manner.

Sandblasting is a conventional method for surface treatment. Amalgam surface after sandblasting showed scratched irregularities that may have positive effect on achieving higher bond strength. Several studies showed that this method can be beneficial for providing enough bond strength..$^{10,11}$

Skilton et $\mathrm{al}^{12}$ in assessing the shear bond strength of brackets bonded to amalgam surfaces roughened by diamond bur or sandblasted by aluminum oxide concluded that sandblasting is more effective for providing higher shear bond strength compared to bur.

Er:YAG laser can ablate amalgam, which was reported by
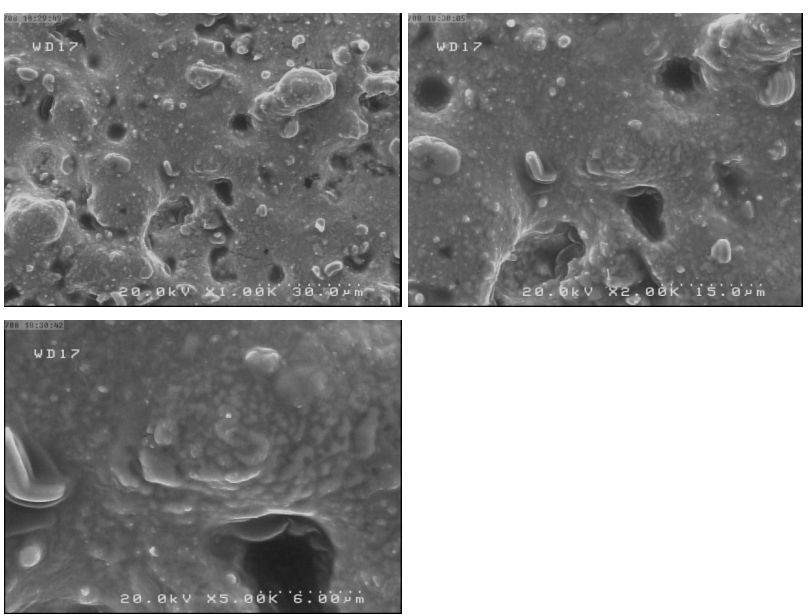

Figure 3. Amalgam surface treated by Er:YAG laser with output power of $3 \mathrm{~W}, 150 \mathrm{~mJ}$ (Original magnification $\times 1000$, x2000, and x5000).
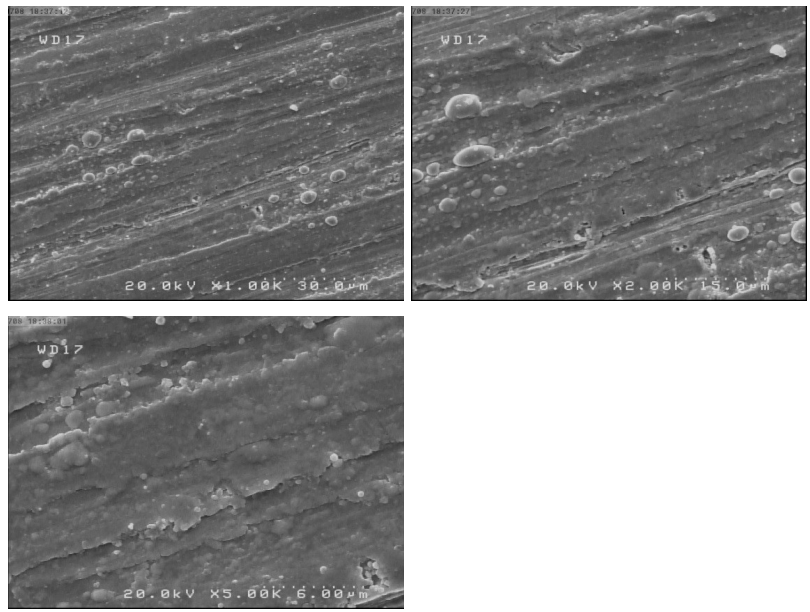

Figure 4. Amalgam surface sandblasted (Original magnification $\mathrm{x} 1000, \mathrm{x} 2000$, and $\mathrm{x} 5000$ ). 

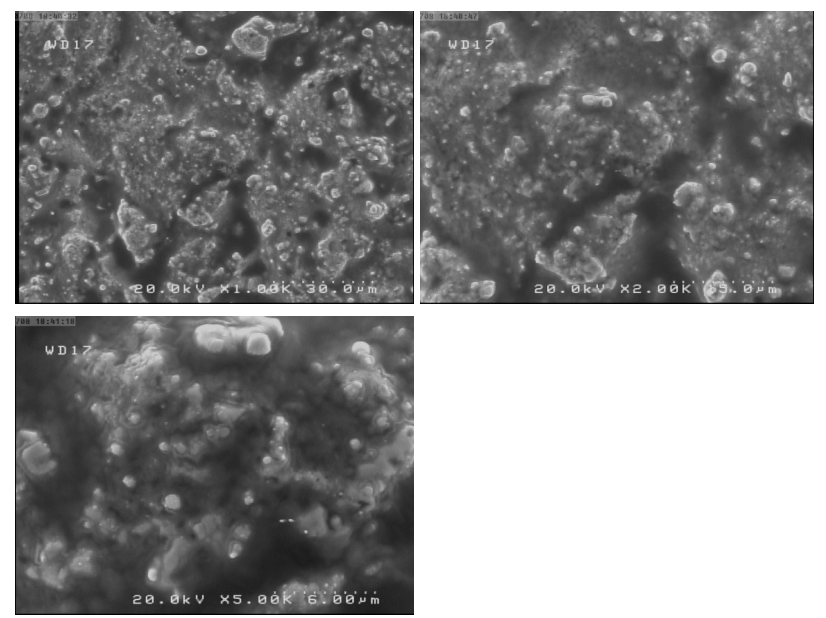

Figure 5. Amalgam surface sandblasted + Er:YAG laser irradiation with output power of $1 \mathrm{~W}, 50 \mathrm{~mJ}$ (Original magnification $\mathrm{x} 1000, \mathrm{x} 2000$, and x5000).

Hibst and Keller. Water irrigation does not have an effect on ablation efficacy. It can just control the temperature rise. ${ }^{7}$ SEM images showed micro-irregularities after laser irradiation on amalgam surfaces.

Oskoee et $\mathrm{al}^{8}$ in the evaluation of Er;Cr:YSGG laser on conditioning amalgam surfaces for bracket bonding compared to sandblasting technique came to the conclusion that erbium laser had positive effect on shear bond strength of brackets to amalgam.

Despite surface evaluation, mercury vapor release during laser ablation should be considered as a hazardous factor for dental staffs. ${ }^{13}$

Further studies are needed to assess the bond strength of orthodontic brackets to amalgam restorations besides mercury vapor release and thermal changes evaluation.

\section{Conclusion}

Based on SEM results, the application of sandblasting technique accompanied by Er:YAG laser irradiation can provide suitable surface for bonding of brackets.

\section{Conflict of Interest}

The authors have no conflict of interest to declare.

\section{References}

1. Keim RG, Gottlieb EL, Nelson AH, Vogels DS. JCO study of orthodontic diagnosis and treatment procedures. Part 1. Results and trends.J Clin Orthod. 2002;36:553-568.

2. Zachrisson BU, Buyukyilmaz T, Zachrisson YO. Improving orthodontic bonding to silver amalgam. Angle Orthod. 1995;65:35-42.

3. Germec D, Cakan U, Ozdemir FI, Arun T, Cakan M. Shear bond strength of brackets bonded to amalgam with different intermediate resins and adhesives. Eur J Orthod. 2009;31(2):207-212. doi:10.1093/ejo/cjn086.

4. Buyukyilmaz T, Zachrisson BU. Improved orthodontic bonding to silver amalgam. part 2. Lathe-cut, admixed, and spherical amalgams with different intermediate
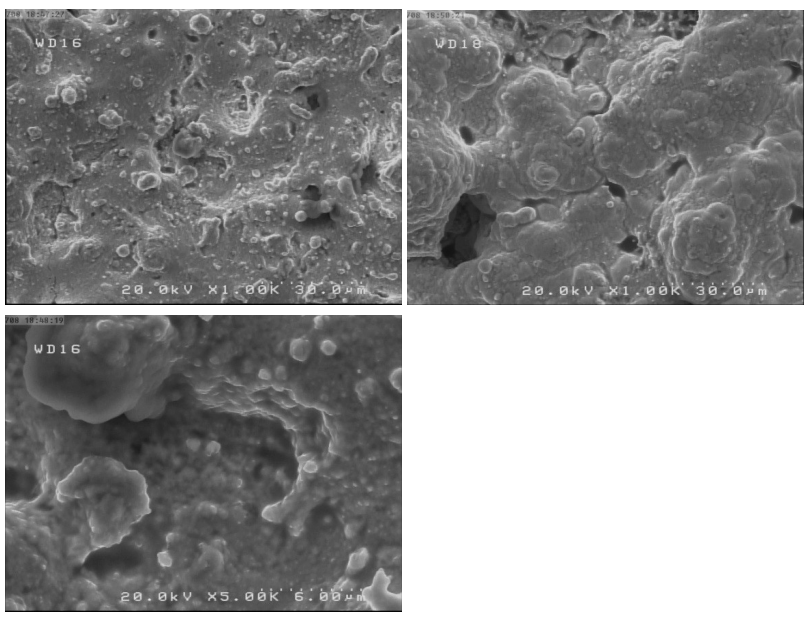

Figure 6. Amalgam surface sandblasted + Er:YAG laser irradiation with output power of $2 \mathrm{~W}, 100 \mathrm{~mJ}$ (Original magnification x1000, x2000, and x5000).

resins. Angle Orthod. 1998;68:337-344.

5. Harari D, Aunni E, Gillis I, Redlich M. A new multipurpose dental adhesive for orthodontic use: an in vitro bond-strength study. Am J Orthod Dentofacial Orthop. 2000;118:307-310. doi:10.1067/ mod.2000.103779

6. Hosseini MH, Namvar F, Chalipa J, et al. Comparison of shear bond strength of orthodontic brackets bonded to enamel prepared by Er: YAG laser and conventional acid-etching. J Dent (Tehran). 2012;9(1): 20-26.

7. Hibst R, Keller U. Removal of dental filling materials by Er:YAG laser. Lasers in Orthopedic, Dental and Veterinary Medicine. Proc SPIE 1424. May 1, 1991. doi:10.1117/12.43998

8. Oskoee PA, Kachoei M, Rikhtegaran S, Fathalizadeh F, Navimipour EJ. Effect of surface treatment with sandblasting and Er,Cr:YSGG laser on bonding of stainless steel orthodontic brackets to silver amalgam. Med Oral Patol Oral Cir Bucal. 2012;17(2):e292-e296. doi:10.4317/medoral.17473

9. Sperber RL, Watson PA, Rossouw PE, Sectakof PA. Adhesion of bonded orthodontic attachments to dental amalgam: In vitro study. Am J Orthod Dentofacial Orthop. 1999;116(5):506-513. doi:10.1016/s08895406(99)70180-0

10. Jost-Brinkmann PG, Drost C, Can S. In-vitro study of the adhesive strengths of brackets on metals, ceramic and composite. Part 1: Bonding to precious metals and amalgam. J Orofac Orthop. 1996;57:76-87.

11. Atta MO, Smith BG, Brown D. Bond strengths of three chemical adhesive cements adhered to a nickelchromium alloy for direct bonded retainers. J Prosthet Dent. 1990;63:137-143.

12. Skilton JW, Tyas MJ, Woods MG. Effects of surface treatment on orthodontic bonding to amalgam. Aust Orthod J. 2006;22(1):59-66.

13. Cernavin I, Hogan SP. The effects of the Nd:YAG laser on amalgam dental restorative material. Aust Dent J. 1999;44(2):98-102. doi:10.1111/j.1834-7819.1999. tb00208.x 